\title{
Oxidation of $o$-chloro and $o$-hydroxy benzyl alcohols catalyzed by copper (II) tetraphenylporphyrin nanoparticles synthesized by mixed solvent method
}

\author{
Rahmatollah Rahimi*, Ensieh Gholamrezapor, Mohammad Reza Naimi-Jamal, Mahboubeh \\ Rabbani
}

Department of Chemistry, Iran University of Science and Technology, Narmak, 16846-13114, Tehran, Iran

\begin{tabular}{|c|c|}
\hline ART I C L E I N F O & A B S T R A T T \\
\hline $\begin{array}{l}\text { Article history: } \\
\text { Received May } 30,2012 \\
\text { Received in Revised form } \\
\text { June 2, } 2012 \\
\text { Accepted } 24 \text { June } 2012 \\
\text { Available online } \\
\text { 27 June 2012 }\end{array}$ & $\begin{array}{l}\text { Tetraphenylporphyrin (TPP) and copper tetraphenylporphyrin (CuTPP) were synthesized and } \\
\text { characterized by IR, UV-Vis, }{ }^{1} \mathrm{HNMR} \text { and }{ }^{13} \mathrm{CNMR} \text {. The CuTPP nanoparticles were } \\
\text { synthesized by sonication and mixed solvent methods. These nanoparticles were characterized } \\
\text { by AFM and SEM images and UV-Vis spectra. The catalytic activity of nanoparticles was } \\
\text { investigated by oxidation of } o \text {-choloro and } o \text {-hydroxy benzyl alcohols in presence of molecular } \\
\text { oxygen and isobutyraldehyde. The yields of oxidation of } o \text {-hydroxy benzyl alcohol by the two }\end{array}$ \\
\hline $\begin{array}{l}\text { Keywords: } \\
\text { Copper (II) tetraphenylporphyrin } \\
\text { Nanoparticles }\end{array}$ & $\begin{array}{l}\text { oxidation at the presence of CuTPP NPs catalyst is very high but selectivity for both reactants } \\
\text { is } 100 \% \text {. }\end{array}$ \\
\hline
\end{tabular}

Molecular oxygen

Benzyl alcohol

Oxidation

\section{Introduction}

In recent years, studies on organic nanoparticles (NPs) such as dyes and porphyrin compounds have attracted more attentions toward this area ${ }^{1-7}$. The preparation and characterization of steady nano organic compounds (NPs) with low molecular weight have not been reported yet. Therefore, efforts to prepare stable and self-standing pure organic NPs are highly demanded, due to this fact, some researches $^{2-5}$ took place to increase the appropriate properties of organic NPs. The porphyrin NPs were synthesized by reprecipitation technique ${ }^{9-10}$, in this method, a solution of organic compound is added to excess amount of poor solvent, with or without surfactant, and as a result the nano-sized particles are precipitated, the simplicity of this technique is a great advantage for preparing of the

* Corresponding author. Tel: +982177240000

E-mail addresses: rahimi_rah@iust.ac.ir(R. Rahimi) 
organic $\mathrm{NPs}^{2-4,11-12}$. A various derivatives of tetraphenylporphyrin and related metalloporphyrin complexes have received more attention due to their important role in biological systems, solar energy conversion, and catalytic activity ${ }^{7-8,13-15}$. The porphyrin molecules aggregate under certain conditions and this event has been studied by a number of research groups for last two decades ${ }^{15,16,19}$. Nowadays, the aggregation of porphyrin derivatives have been considered for synthesizing the nanostructure materials ${ }^{7,16-19}$. In all instances, $\pi-\pi$ interaction plays the most effective role in forming the aggregated structures ${ }^{10}$. Porphyrin NPs are promising components of advanced materials ${ }^{13}$ because of their outstanding properties like rich photochemistry, stability and proven catalytic activity. The porphyrin NPs have unique catalytic properties that are not available in larger-scaled materials containing the macrocycle $\mathrm{e}^{20-22}$. The oxidation of benzyl alcohols to the corresponding carbonyl compounds is an important and usual catalytic conversion in laboratory chemistry and in chemical industry for synthesis of many medicinal compounds ${ }^{22-33}$.

In order to avoid using toxic and dangerous oxidants, oxidative catalytic conversion of organic molecules has been developed in the recent years by using environmentally clean oxidants such as molecular oxygen or hydrogen peroxide. For example, benzyl alcohols have been oxidized by molecular oxygen, because this oxidant only produces water as a by product ${ }^{34,35}$, the other advantages are also, low-price, secure and high availablity ${ }^{33,34}$. The several other simple systems have been reported for the oxidation of benzyl alcohols in presence of porphyrin complexes as catalyst and $\mathrm{O}_{2}$ as oxidant ${ }^{24-32}$. For the first time, the iron porphyrin complexes have been reported by Han et al as a good catalyst for oxidation of benzyl alcohols to the carbonyl compounds ${ }^{29}$. In general, the electron withdrawing groups in the phenyl ring of the benzyl alcohols have given lesser yield in oxidation processes ${ }^{37-40}$. In this study, we reported the synthesis and characterization of CuTPP NPs, and then the catalytic activity of produced NPs for oxidation of two different benzyl alcohols was investigated. The obtained results of catalytic activity of CuTPP NPs were compared with those of CuTPP.

\section{Results and Discussion}

\subsection{Characterization of the metalloporphyrin NPs}

The substances TPP and CuTPP were synthesized according to Adler et al method ${ }^{41}$, but the CuTPP NPs were prepared according to Xianchang Gong et al method ${ }^{19}$ (Scheme 1). The UV-Vis spectra of CuTPP NPs are considerably different compared to the spectra of the corresponding porphyrin (Fig. 1), the Soret band of NPs were found to be broadened and splitted.
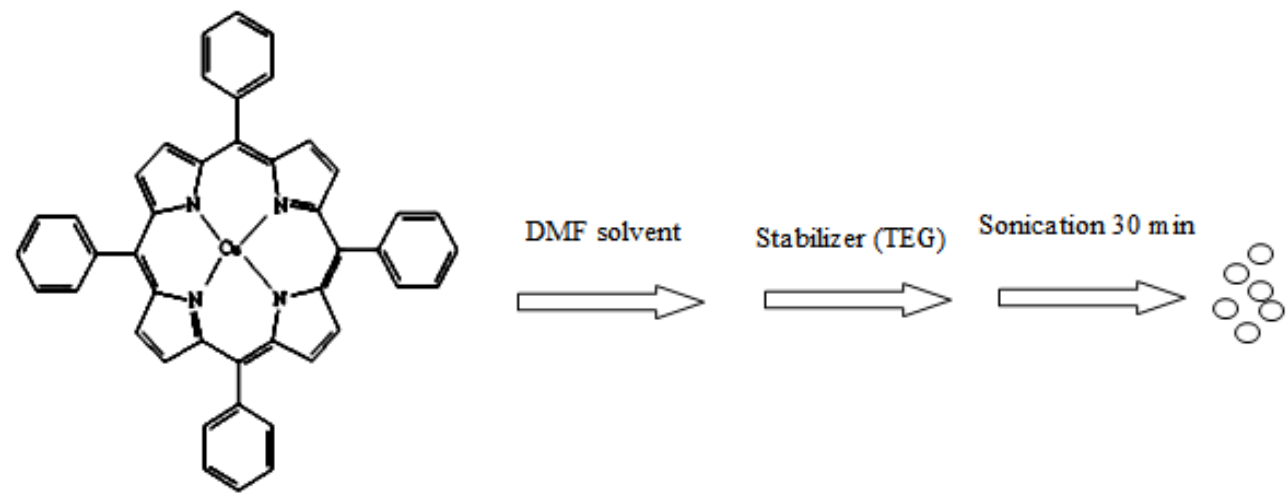

Scheme 1. Synthesis of CuTPP NPs steps 


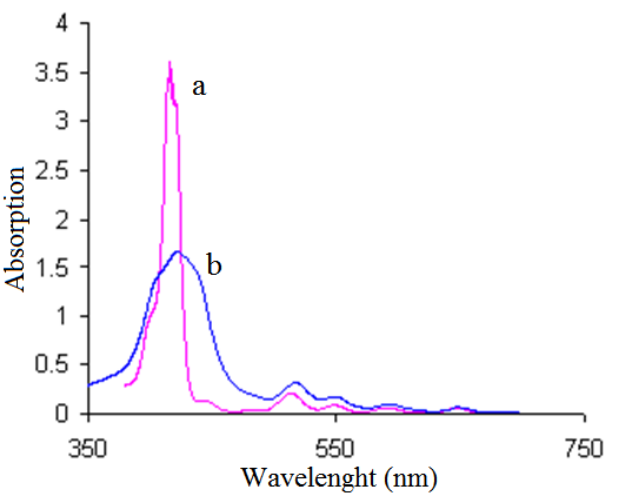

Fig. 1.UV-Vis spectra of (a) CuTPP (b) CuTPP NPs

The optical spectrum of copper porphyrin NPs in chloroform (Fig. 1b) shows that porphyrins are aggregated in two types of arrangement, they are known as "J" (edge to edge) and "H" (face to face). In addition to the splitting and broadening of soret band, the red-shift of Q-bands in the optical spectra takes place in agglomeration of the NPs ${ }^{16}$. The porphyrin NPs are likely held together by $\pi$ stacking effects, and their stabilities after months of storage are proven by unchanged optical spectrum $^{12,16}$. In this work, These NPs were tested for stability in solution, no precipitation occurred after being stored in dark at room temperature for 30 days.
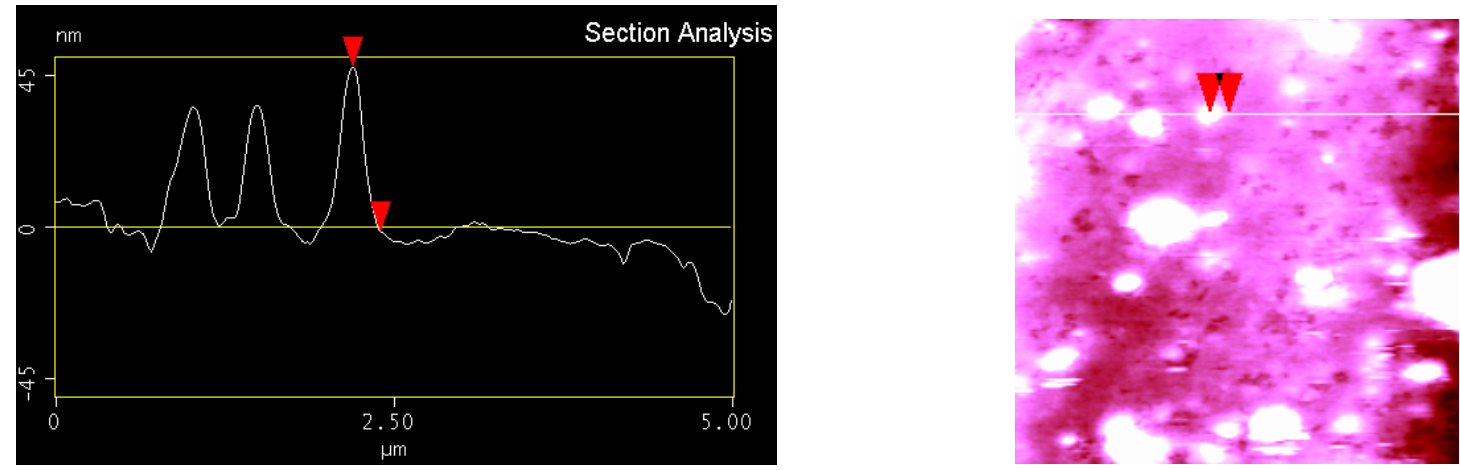

Fig. 2. AFM image and analysis of CuTPP NPs

Fig. 2a

Fig. 2b

The reliable data of CuTPP NPs by Atomic force microscopy (AFM) (Fig. 2), gives the height of the NPs 50-200 nm. The SEM image of the porphyrin NPs morphology is shown in Fig. 3. According to the SEM image, the particles are spherical in shape, the average particles diameter is $48 \mathrm{~nm}$ and the size distribution of the NPs is extremely narrow, these images confirm the preparation of porphyrin NPs via ultrasonic method.

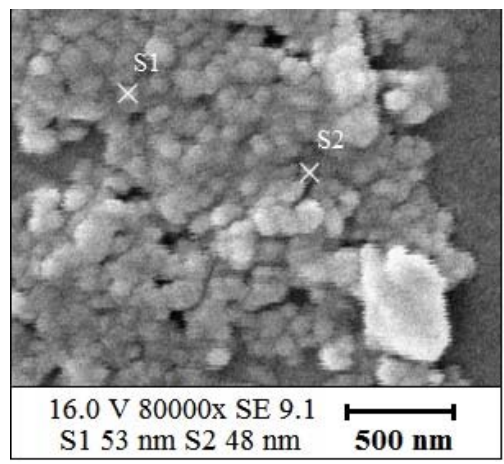

Fig. 3. SEM image of CuTPP NPs 


\subsection{Catalytic activities}

In this study, the catalytic activity of CuTPP NPs and CuTPP was investigated for oxidation of $o-$ chloro and $o$-hydroxy benzyl alcohols, the oxidation of these substrates was performed in the presence of molecular oxygen and isobutyraldehyde, as $\mathrm{O}_{2}$ acceptor in DMF solvent. The percent yields of product for the reaction was very high at the presence of CuTPP NPs catalyst after $37 \mathrm{~h}$ at $60^{\circ} \mathrm{C}$ in DMF solvent (Scheme 2). The results of oxidation of $o$-chloro and $o$-hydroxyl benzyl alcohols in presence above catalysts were exhibited in Table 1. All yields were detected by GC instrument. By comparing the effects of CuTPP NPs and CuTPP on the amount of yields; it is clear that the oxidation at the present of CuTPP NPs catalyst is very high.

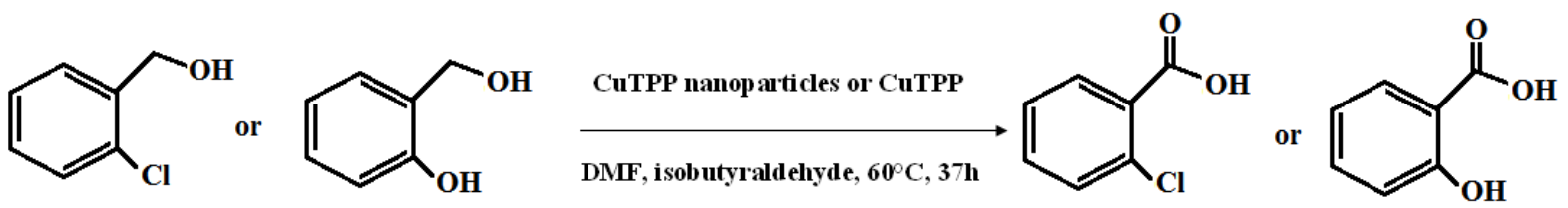

Scheme 2. Oxidation of $o$-chloro and o-hydroxy benzyl alcohols in presence of CuTPP NPs

Table 1

Oxidation in presence of CuTPP NPs sand CuTPP

\begin{tabular}{cccccc}
\hline & \multicolumn{2}{c}{ CuTPP nanoparticles } & \multicolumn{2}{c}{ CuTPP } \\
\cline { 2 - 5 } Yield (\%) & Selectivity (\%) & Yield (\%) & Selectivity (\%) \\
\hline
\end{tabular}

\section{Conclusions}

The compounds of TPP and CuTPP were synthesized, and characterized by UV-Vis, IR, ${ }^{1} \mathrm{HNMR}$ and ${ }^{13} \mathrm{CNMR}$. The CuTPP NPs were also synthesized by simple method of sonication and mixed solvents. These organic NPs were characterized by AFM and SEM images and UV-Vis spectra. Then catalytic activity of CuTPP NPs and TPP were investigated in presence of molecular oxygen and isobutyraldehyde. The studies exhibited good catalytic activity of CuTPP NPs for oxidation of benzyl alcohols rather than CUTPP due to larger surface area and the aggregated structure.

\section{Acknowledgement}

We thank the Iran University of Science and Technology for the financial support to this research

\section{Experimental}

\section{Materials and Methods}

The materials like pyrrole, benzaldehyde, methanol, chloroform, dimethylformamide (DMF), $\mathrm{Cu}(\mathrm{OAc})_{2}$, propionic acid, triethylene glycol monomethyl ether (TEG) and $o$-chloro and $o$-hydroxy 
benzaldehydes were purchased from Merck chemical company. The free base porphyrin $\mathrm{TPPH}_{2}$ was prepared and purified by methods reported already ${ }^{41}$. The Scanning electron microscopy was performed by SEM instrument (model XL30) made Philips company. For taking SEM images, a drop of colloid solution was placed on glass, coated with gold and then sample was placed in SEM instrument. The atomic force microscopy (AFM, Nano Scope II from digital Instruments Inc., CA, USA in contact mode) was used for surface morphology analysis and size distribution of the NPs. The UV-Visible absorption spectroscopy (Shimadzu- 1700 model, pharmaspec) was used to inscribe adsorption behavior. ${ }^{1} \mathrm{H}$ and ${ }^{13} \mathrm{CNMR}$ spectra were recorded on a Bruker DRX-300 Avance spectrometer at $500 \mathrm{MHz}$ in $\mathrm{CDCl}_{3}$ using TMS as external standard. Infrared spectra $\left(4000-400 \mathrm{~cm}^{-1}\right)$ of solid sample were taken as $1 \%$ dispersion in $\mathrm{KBr}$ pellets using a FTIR-8400S Shimadzu spectrophotometer. The analysis of the reaction product was performed by using GC instrument (SHIMADZU-2010) equipped with a flame ionization detector and OMEGAWAX-250 capillary column $(30 \times 0.25 \mathrm{~mm}$ i.d. $)$. The injection and detector temperature were set at $250^{\circ} \mathrm{C}$, Helium $(99.999 \%)$ was used as carrier gas with a flow rate of $1.15 \mathrm{ml}$ per min and nitrogen $(99.999 \%)$ was used as make up gas. The injection volume of all samples was $1 \mu l$.

\section{General procedure}

\section{Synthesis of TPP and CuTPP}

Tetraphenylporphyrin (TPP) was synthesized by refluxing the benzaldehyde and fresh distilled pyrrole in the propionic acid solvent ${ }^{41}$. The purification of the porphyrin was done by column chromatography with chloroform as eluent. The CuTPP was synthesized by refluxing TPP and $\mathrm{Cu}(\mathrm{OAc})_{2}$ in mixed solvent of methanol/chloroform according to the previous technique ${ }^{19}$.

\section{Preparation of metalloporphyrin NPs}

The Porphyrin NPs were prepared using mixed solvents of DMF/water and sonication techniques according to the Xianchang Gong et al method. ${ }^{19}$. Amount of $1.5 \mathrm{mg}(0.002 \mathrm{mmol}) \mathrm{CuTPP}$ was dissolved in $4 \mathrm{ml} \mathrm{DMF}$ solvent. Then, amount of $0.4 \mathrm{ml}$ of the above solution was taken and $50 \mu \mathrm{l}$ of stabilizer (TEG) was injected into it, followed by adding rapidly $5 \mathrm{ml}$ of deionized water at room temperature under strong sonicated condition for 30 minutes. A very light yellow colloid was obtained and used for characterization and catalytic study.

\section{The oxidation process of benzyl alcohols}

The amount of 0.002 mmol CuTPP NPs were added to $o$-chloro or $o$-hydroxy benzyl alcohol (2 $\mathrm{mmol})$ and isobutyraldehyde $(6 \mathrm{mmol})$ in $10 \mathrm{ml} \mathrm{DMF}$, the solution was refluxed at $60^{\circ} \mathrm{C}$ for $37 \mathrm{~h}$ in the presence of molecular oxygen. For the above reaction, CuTPP NPs were replaced by CuTPP and other conditions were remained the same.

\section{Physical and Spectral Data}

TPP:

${ }^{1} \mathrm{HNMR}\left(500 \mathrm{MHz}, \mathrm{CDCl}_{3}, \delta\right)$ ppm: 8.20-8.23 (m, 8 ortho-H), 7.72-7.79 (m, 12 para, meta-H), 8.84 (s, 8 pyrrole-H), -2.0 (br s, $2 \mathrm{H}, \mathrm{NH}) .{ }^{13} \mathrm{CNMR}\left(500 \mathrm{MHz}, \mathrm{CDCl}_{3}, \delta\right.$ ) ppm: 120 (meso-C), $142.5(\alpha-$ C), $128(\beta-\mathrm{C}), 126-135$ (Aromatic carbons). Visible $\left(\mathrm{CH}_{2} \mathrm{Cl}_{2}\right) \lambda_{\max }, \mathrm{nm}(\varepsilon)$ : soret band (418), Q band $(645,548,414,589)$. IR (KBr) cm $\mathrm{cm}^{-1}: 3300(\mathrm{~N}-\mathrm{H}), 1420(\mathrm{C}-\mathrm{N}), 1550$ (C Aromatic) and $3020(\mathrm{C}-\mathrm{H})$. CuTPP: 
${ }^{1} \mathrm{HNMR}\left(500 \mathrm{MHz}, \mathrm{CDCl}_{3}, \delta\right)$ ppm: 7.48 (meta-H), 7.62 (para-H). Visible $\left(\mathrm{CH}_{3} \mathrm{Cl}\right) \lambda_{\max }, \mathrm{nm}(\varepsilon)$ : soret band (414), Q band (537). IR (KBr) cm ${ }^{-1}: 1420(\mathrm{C}-\mathrm{N}), 1550(\mathrm{C}$ Aromatic), $2850(\mathrm{C}-\mathrm{H})$ and $478(\mathrm{Cu}-$ $\mathrm{N})$.

\section{References}

1. Seko T., Ogura K., Kawakami Y., Sugino H., Toyotama H., Tanaka J. (1998) Excimer emission of anthracene, perylene, coronene and pyrene microcrystals dispersed in water. $J$. Chem .Phys. Lett., 291, 438-444.

2. $\quad$ Wang Y., Deng K., Gui L., Tang Y., Zhou J.,Cai L., Qiu J., Ren D. (1999) Preparation and Characterization of Nanoscopic Organic Semiconductor of Oxovanadium Phthalocyanine. $J$. Colloid Interface. Sci., 213, 270-272.

3. Kasai H., Oikawa H., Okada S., Nakanishi H. (1998) Crystal Growth of Perylene Microcrystals in the Reprecipitation Method. Bull. Chem. Soc. Jpn. 71, 2597-2601.

4. Matsuda H., Yamada S., Keuren E. V., Katagi H., Kasai H., Okada S., Oikawa H., Nakanishi H., Smith E. C., Kar A. K., Wherrett B. S. (1997) Nonlinear refractive indexes of polydiacetylene microcrystals. Proc. SPIE., 2998, 241-248.

5. Tamaki Y., Asahi T., Masuharam H. (2000) Tailoring nanoparticles of aromatic and dye molecules by excimer laser irradiation. Appl. Surf. Sci., 168, 85-88.

6. Fu H. B., Yao J. N. (2001) Size Effects on the Optical Properties of Organic Nanoparticles. J. Am. Chem. Soc., 123, 1434-1439.

7. Fu H. B., Ji X. H., Yao J. N. (1999) The Size-dependent Property of 1,3,5-Triphenyl-2pyrazoline Microcrystals. J. N. Chem. Lett., 9, 967-968.

8. Arun K. P., Prakriti R.B. (2008) Preparation and Characterization of free -standing pure porphyrin nanoparticles. J. Chem. Sci. 120, 485-491.

9. Zhong M. O., Hiroshi Y., Keisaku K. (2007) Preparation and optical properties of organic nanoparticles of porphyrin without self-aggregation. J. Photo. Chem. Photo. Bio. A: Chem., 189, 7-14.

10. Kashani-Motlagh M. M., Rahmatollah R., Javaheri-Kachousangi M. (2010) Ultrasonic method for the preparation of organic porphyrin nanoparticles, Molecules, 15, 280-287

11. Drain C. M., Nifiatis F., Vasenko A., Batteas J. D. (1998) Porphyrin tessellation by design: metal-mediated self-assembly of large arrays and tapes. Angew. Chem. Int. Ed. En., 37(17), 2344-2347.

12. Xu. W, Guo H., Akins D .L. (2001) Aggregation of Tetrakis(p-sulfonatophenyl) porphyrin within modified mesoporous MCM-41. J. Phys. Chem. B., 105, 1543-1546.

13. Akins D. L., Zhu H. R., Guo C. (1996) Aggregation of tetraaryl substitutedporphyrins in homogeneous solution. J. Phys. Chem., 100, 5420-5425.

14. Chou J. H., Kosal M. E., Nalwa H. S., Rakow N. A., Suslick K. S., Kadish K. M., Guilard R., Eds (2000) The porphyrin Handbook. Academic Press: New York, 6, 43-131.

15. Yoshiaki T., Tsuyoshi A., Hiroshi M. (2002) Nanoparticle formation of vanadyl phthalocyanine by laser ablation of its crystalline powder in a poor solvent. J. Phys. Chem. A, 106, 2135-2139.

16. Maiti N. C., Mazumdar S., Periasamy N. (1998) J- and H-Aggregates of porphyrin-surfactant complexes: time-resolved fluorescence and other spectroscopic studies. J. Phys. Chem. B, 102, 1528-1538.

17. Arun K. P., Prakriti R. B. (2008) Preparation and characterization of free-standing pure porphyrin nanoparticles. J. Chem. Sci., 120, 485-491.

18. Faulkner K. M., Liochev S. I., Fridovich I. (1994) Stable Mn(III) porphyrins mimic superoxide dismutase in vitro and substitute for it in vivo. J. Biol. Chem., 269 (38), 2347123476

19. Xianchang G., Tatjana M., Chang X., James D. B. Charles M. D. (2002) Preparation and Characterization of Porphyrin Nanoparticles. J. Am. Chem. Soc., 124, 14290-14291. 
20. Ghosh A., Selvamani T., Jose D. A., Das A., Mukhopadhyay I. (2007) Generation of nanostructures by the aggregation of porphyrin derivatives with long alkane chain in mixsolvent. J. Nanomater., Article ID 47234, doi:10.1155/2007/47234, 8 pages.

21. Debuigne F., Jeunieau L., Wiame M., Nagy J. B. (2000) Synthesis of Organic Nanoparticles in Different W/O Microemulsions. Langmuir, 16 (20), 7605-7611.

22. Tabushi I., Koga N. (1979) Synergetic combination of catalysis of the phase transfer-electron transfer type for the oxidation of alcohols or hydrocarbons. Tetrahedron Lett., 20, 3681-3684.

23. Labat G., Meunier B. (1989) Factors controlling the reactivity of a ligninase model based on the association of potassium monopersulfate to manganese and iron porphyrin complexes. $J$. Org. Chem., 54, 5008-5011.

24. Wietzerbin K., Meunier B., Bernadou J. (1997) Oxidation of tertiary diaryl alcohols catalyzed by a water-soluble metalloporphyrin: $\mathrm{C}_{\text {aliph }}-\mathrm{C}_{\text {aliph }}$ versus $\mathrm{C}_{\mathrm{aliph}}-\mathrm{C}_{\mathrm{Ar}}$ bond cleavage. J. Chem. Commun., 23, 2321-2322.

25. Baciocchi E., Belvedere S. (1998) oxidation of $\alpha$-Alkylbenzyl Alcohols Catalysed by 5,10,15,20-Tetrakis(pentafluorophenyl)porphyrin Iron(III) Chloride Competition between C$\mathrm{H}$ and C-C Bond Cleavage. Tetrahedron Lett., 39, 4711-4714.

26. Campestrini S., Cagnina A. (1999) A mechanistic study on oxidation of benzylic alcohols with $\mathrm{PPh}_{4} \mathrm{HSO}_{5}$ catalysed by manganese_(III) porphyrins in homogeneous solution. J. Mol. Catal. A: Chem., 150, 77-86.

27. Moghadam M., Tangestaninejad S., Mirkhani V., Mohammadpoor-Baltork I. ,Kargar H. (2005) Mild and efficient oxidation of alcohols with sodium periodate catalyzed by polystyrene-bound Mn(III) porphyrin. Bioorg. Med. Chem., 13, 2901-2905.

28. Naik R., Joshi P., Deshpande R. K. (2005) Immobilization of metallporphyrins on polystyrene: Efficient catalysts for aerobic oxidation of alcohols. J. Mol. Catal. A: Chem., 238, 46-50.

29. Han J. H., Yoo S. K., Seo J. S., Hong S. J., Kim S. K., Kim C. (2005) Biomimetic alcohol oxidations by an iron(III) porphyrin complex: relevance to cytochrome P-450 catalytic oxidation and involvement of the two-state radical rebound mechanism. Dalton Trans., 2, 402-406.

30. Oh N. Y., Suh Y., Park M. J., Seo M. S., Kim J., Nam W. (2005) Mechanistic insight into alcohol oxidation by high-valent iron-oxo complexes of heme and nonheme ligands. Angew. Chem. Int. Ed., 44, 4235-4239.

31. Huang J. Y., Li S, J., Wang Y. G.(2006) TEMPO-linked metalloporphyrins as efficient catalysts for selective oxidation of alcohols and sulfides. Tetrahedron Lett., 47, 5637-5640.

32. Schults M. J., Sigman M. S. (2006) Recent advances in homogeneous transition metalcatalyzed aerobic alcohol oxidations. Tetrahedron, 62, 8227-8241.

33. Jiang N., Ragauskas A. J. (2007) Vanadium-catalyzed selective aerobic alcohol oxidation in ionic liquid [bmim] $\mathrm{PF}_{6}$. Tetrahedron Lett., 48, 273-276.

34. Huang G., Luo J., Deng C. C., Guo Y. A., Zhao S. K.,Zhou H.,Wei S. (2008) Catalytic oxidation of toluene with molecular oxygen over manganese tetraphenylporphyrin supported on chitosan. Appl. Catal. A: Gen., 338, 83-86.

35. Yuan Y., Ji H., Chen Y., Han Y.,Song X., She Y., Zhong R. (2004) Oxidation of cyclohexane to adipic acid using fe-porphyrin as a biomimetic catalyst. Org. Process Res. Dev., 8, 418420.

36. Zhou X. T., Ji H. B., Cheng Z., Xu J. C., Pei L. X., Wang L. F. (2007) Selective oxidation of sulfides to sulfoxides catalyzed by ruthenium(III) meso-tetraphenylporphyrin chloride in the presence of molecular oxygen. Bioorg. Med. Chem. Lett., 17, 4650-4653.

37. Jain S. L., sain B. (2001) Cobalt phthalocyanine tetrasulphonamide catalyzed aerobic oxidation of $\alpha$-hydroxyketones: an efficient and simple synthesis of $\alpha$-diketones, J. Mol. Catal. A: Chem., 176, 101-104. 
38. Santos I. C. M. S., Rebelo S. L. H., Baluda M. S. S., Martins R. R. L., Pereira M. M. M. S., Simoes M. M. Q., Neves M. G. P. M. S., Cavaleiro J. A. S., Cavaleiro A. M. V. (2005) Association of Keggin-type anions with cationic meso-substituted porphyrins: synthesis, characterization and oxidative catalytic studies. J. Mol. Catal. A: Chem., 231, 35-45.

39. Giri N. G., Chauhan S. M. S. (2009) Oxidation of polycyclic aromatic hydrocarbons with hydrogen peroxide catalyzed by iron(III) porphyrins. Catal. Commun., 10, 383-387.

40. Rayati S., Zakavi S., Motalagh S. H., Noroozi, Razmjoo M., wojtczak A., Kozakiewicz A. (2008) $\beta$-Tetra-brominated meso-tetraphenylporphyrin V. A conformational study and application to the Mn-porphyrin catalyzed epoxidation of olefins with tetrabutylammoniumoxone. Polyhedron, 27, 2285-2290.

41. Adler A.D., Longo F. R., Finarelli J. D., Goldmacher J., Assour J., Korsakoff L. (1967) A simplified synthesis for meso-tetra phenylporphyrine. J. Org. Chem., 32, 476-476. 